\title{
Research on the feasibility of large-span cable structure under impact
}

\author{
L.LIN ${ }^{1,2}$, M.Y.HUANG ${ }^{1} \& Y . H . S U N^{1} \& X . Q . S O N G^{1} \& J . L I$ \\ ${ }^{1} \& Z . Y . G U O^{1} \& X . D . W A N G^{1, *}$ \\ 1,College of Civil Engineering and Architecture, Harbin University of Science and Technology, \\ Harbin, PR China \\ 2,School of Civil Engineering, Harbin Institute of Technology, Harbin, PR China \\ 1, College of Civil Engineering and Architecture, Harbin University of Science and Technology, \\ Harbin, PR China
}

\begin{abstract}
KEYWORD: Large-span; Cable structure; Impact; Necessity; Feasibility
ABSTRACT: Recently, large-span cable structures are widely applied in the stadium, exhibition center, airport terminal and other public buildings. At the same time, there are some risks caused by the accidental loading in the application period, such as terrorist attacks, the car collisions, falling objects and windborne debris. Therefore, it is important to improve the defensive ability of largespan cable structure when subjected to impact loading. Yet research on the dynamic responses and failure mechanism of large-span structure under impact load has so far been little, and the effective design method and structural measure in the practical engineering is scarce. Besides, more attention should be paid on performance of large-span cable structure when subjected to impact load.
\end{abstract}

\section{INTRODUCTION}

As China's comprehensive national strength has enhanced steadily, more and more skyscrapers have sprung up like mushroom after rain in various metropolises, and the glass curtain wall of an entire body is favored by a great number of architects because of its incomparable aesthetic value. With the rapid development of economy, people's living standards improve constantly, people have paid more attention to participating in the public events, such as the exhibitions, concerts and sporting events. And the buildings which provide places for the activities usually become the landmark of the country or a region. "Higher, larger span, more unique modeling, more complex shape" is the eternal theme of the modern large-scale public buildings, and it is also a challenge to the workers in construction engineering.

\section{SUMMARY OF CABLE STRUCTURE}

Cable structure is a kind of tensile structure, which can compose different structure systems by a series of tension cable with a certain regularity, and hangs on the supporting structure ${ }^{[1]}$. It is a kind of bearing structure system with a long history, and the tent house in ancient time is the rudiment of suspended roof. In China, the cable bridge was built up by bamboos and iron chains over more than a thousand years ago. The modern long-span cable stayed bridge has appeared since the steel was invented, and was on the rise at the beginning of the $20^{\text {th }}$ century. Since the 1950 s, cable structure has been gradually applied to the house buildings. Cable structure resists loads by the axial tensile ability of cables, and the steel strength can be fully used. Especially the use of steel wire and string, it reduces the self-weight and steel consumption. Therefore, the cable structures become the one of the common structural types in modern long-span buildings.

\section{THE NECESSITY OF LARGE-SPAN CABLE STRUCTURE UNDER IMPACT}

\section{Cable structure is the common structural types of modern large-scale public buildings}

For the reason that the weight of cable is light, we don't need large lifting equipment during the installation process, and it can adapt to all kinds of shapes and express the architectural form freely, the cables are widely used in the large-span roofing structures such as modern stadiums, ex- 
hibitions and museums. In recent years, due to the thin section of cable meets the requirements of the permeability of glass structure, it also is used as a support structure for large-scale glass curtain walls and glass roof. It is a new development of cable structure (see Fig. 1). Therefore, the theory research and practice of cable structure has always been one of the most active fields in structure engineer.
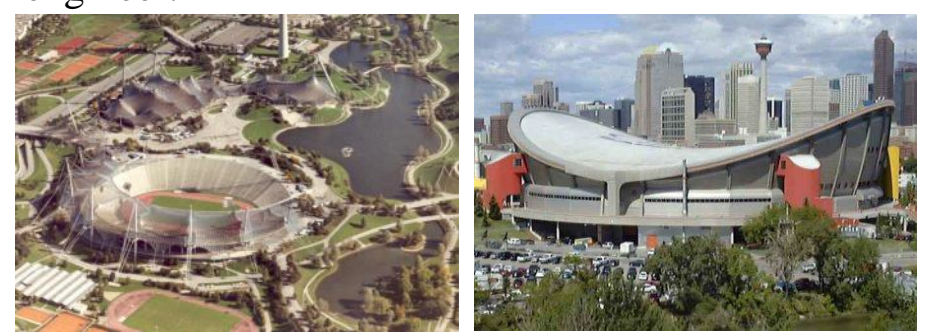

Munich Olympic stadium

The Canadian Saddle dome

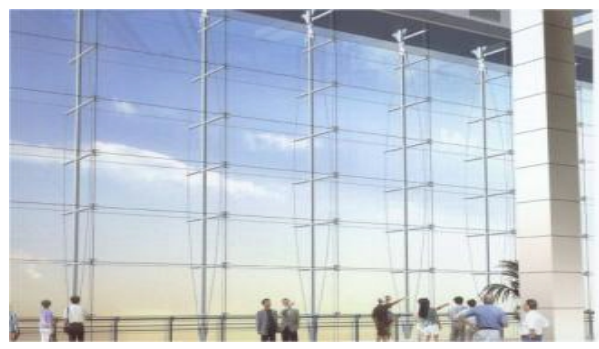

The terminal of Guangzhou New

Baiyun International Airport

Figure 1 The application of cable structure in large public buildings

Beijing has succeeded in bidding for the 2022 Winter Olympic Games, and it has been proposed to keep economic sustainable growth in the Thirteenth Five-year Planning. In consequence, the economy will still keep on growing at a high speed in China, and the demand of large-scale public buildings is increasing, such as exhibition venue, sports center, modern airport and station. In addition, the glass curtain wall structure is developing rapidly towards the direction of large-span, ultra-light and high permeability. What's happening suggests that the cable structure will be flourishing development and applied more widely.

\section{Modern public buildings are threatened by the impact of accidental loading}

As the large-span cable structure is widely applied in large-scale public buildings, people gradually pay more attention to its performance under the impact load. In recent years, the accidental loading including the impact and blast loading caused the structural damage in lots of buildings, such as the speeding car crashed into houses, the falling objects and windborne debris damaged houses, and terrorist attacks occurred.

On December 2, 2012, a semi-trailer rushed into a two-story building near No.329 National Road in Zhejiang Province, damaged the girder and a corner of the building. On August 31, 2014, the tower crane broke off on a construction site in Fushun, the building under construction and scaffold were destroyed by the falling counterweight components. Although the results of two accidents weren't extremely serious, the serious consequences would be hard to imagine if they happened in densely populated public buildings. In addition, "9.11" incident is the most typical terrorist attacks. The impact effect of Boeing707 had been considered when the World Trade Centre designed, but it still took place the progressive collapse after the impact. According to the United Nations, the death toll was 2,996 in "9.11" incident, the economic losses reached 200 billion of dollars in USA and 1 trillion in the whole world. And that caused the serious psychological panic to people of the world, and affected the social production and people's lives. The transportation, tourism and other industries were hard hit by the incident (see Fig. 2). Recently, with the adjustment of world political pattern, terrorist attacks increased gradually which posed a serious threat to the safety of lives and property. 


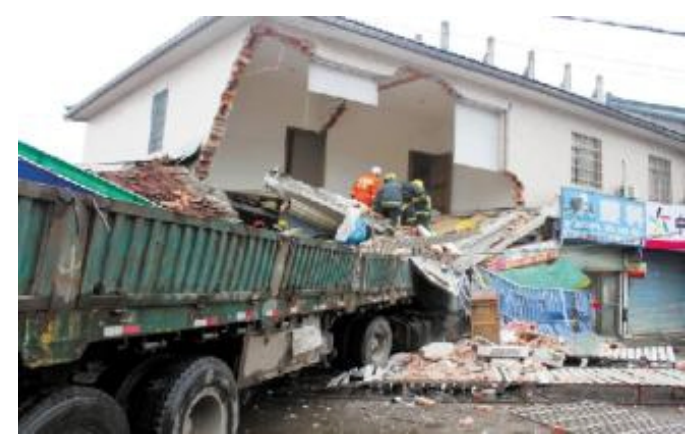

Semi-trailer crashed into the building

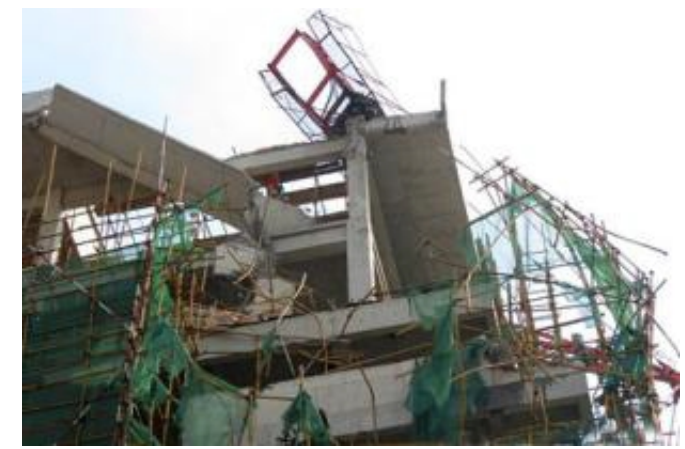

The counterweight of tower crane destroyed the building

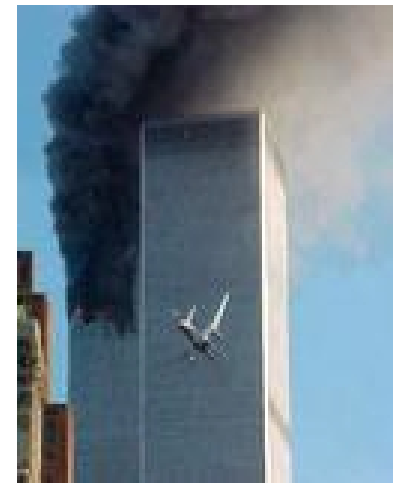

The World Trade Centre was impacted

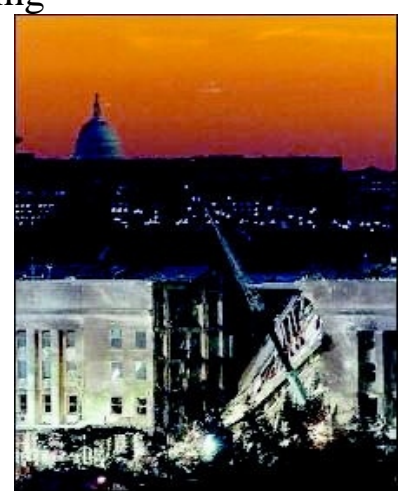

The Pentagon was impacted

Figure 2 Modern public buildings are threatened by the impact of accidental loading

As with the volcanic eruptions, hurricanes and other natural disasters, the accidents above are small probability events. Yet we can't ignore for the reason that the accidental events often occur around the whole world in a certain time period. Besides, the large-scale public buildings are of great political and economic importance. With high-crowded personnel, they become the places where crisis is easy to happen. And it will cause the irreversible damage of economy and people's living if the accidents above occur. Therefore, it need to be consider the performance of structure under the impact loading within the entire life cycle of the building including design, construction and operation.

\section{THE FEASIBILITY OF LARGE-SPAN CABLE STRUCTURE UNDER IMPACT LOAD}

As the increasing of the vehicle impact, falling objects and the other accidental events, it becomes more and more important to research on the dynamic response and failure mode of the structure under the impact loading. Yet research on the performance of large-span cable structure under the impact loading has so far been little, we can study further by referencing the relevant research results. Foreign scholars' studies on the dynamic response and collapse failure of structure were earlier, and they had lots of successful experience. In the 1960s, foreign scholars began their research on struc- 
tural progressive collapse. K.Abedi ${ }^{[2]}$ thought that progressive collapse may be defined as the "widespread propagation of instability following damage to a portion of a structure", and researched on the dynamic propagation of local snap-through in single-layer braced domes. K. A. Steffen ${ }^{[3]}$ briefly analyzed the progressive collapse of the World Trade Center, and proposed the point that the collapse behavior is considered formally as a propagating instability phenomenon. Furthermore, some domestic scholars has been conducted on the impact resistance of structures since the "911" incident. Liang $\mathrm{Yi}$ and other scholars ${ }^{[4]}$ analyzed the capacity to resist the progressive collapse of a typical Chinese 3-story reinforced concrete(RC) frame. Then the frame was re-designed with the Tie Force Method and the Alternate Path Method to provide examples for the progressive collapse prevention design for Chinese frame structures. Professor Hao Hong and members of his team ${ }^{[5]}$ established the numerical models for calculating the blast overpressure loading outside buildings, and proposed to some principles in the design and retrofitting of a blast-resistant building.

The research on impact resistance of large-span space structure started later in Chinese, and the objects of study mostly are reticulated domes, only a bit of research are for the cable loss in cablestayed bridges. Li Haiwang and other scholars ${ }^{[6]}$ studied the dynamic response and stability of reticulated domes under impact with small mass and low speed, it was the earliest experimental study about impact resistance of reticulated domes by using a dropping machine(see Fig. 3).

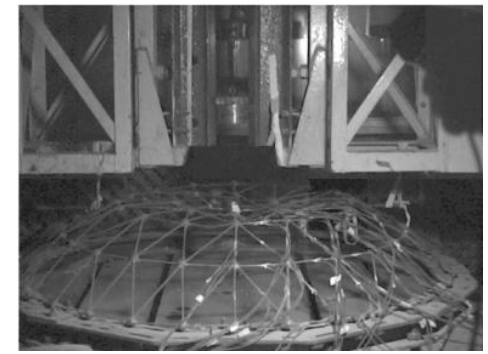

The final deformation

Figure 3 The impact experiment of reticulated dome by using a dropping machine(Source: Li)

Wang Duozhi, Fan Feng and other scholars modeled the single-layer Kiewitt-6 reticulated domes with a span of $60 \mathrm{~m}$, including modal analysis, elastic and destructive impact loading tests by using a dropping machine ${ }^{[7]}$, conducted to verify the numerical model(see Fig. 4), and identified the three failure modes of reticulated domes when subjected to impact load (see Fig. 5). Lin $\mathrm{Li}^{[8]}$ investigated respectively the size effect and material property effect of the impactor on the damage modes of the single-layer Kiewitt- 8 reticulated dome, indicated the failure mechanism of the single-layer Kiewitt-8 reticulated dome when subjected to impact load, and determined the impact failure rule. Ma Jialu investigated the dynamic response, failure modes and failure mechanism of a single-layer reticulated dome when subjected to interior blast loading ${ }^{[9]}$, and established the precise and simple model of single-layer lattice shells in order to predict the blast loading, which is suitable for a wide scope of single-layer lattice shells ${ }^{[10]}$.

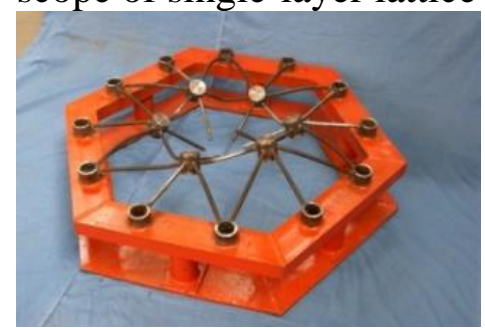

Model-1: Global collapse of dome

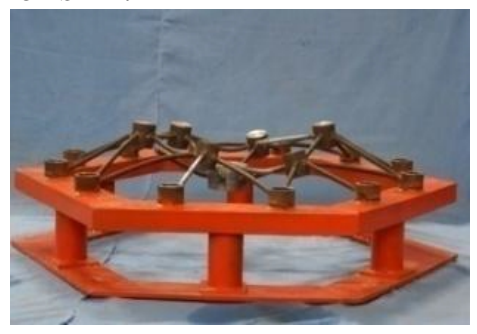

Model-2: Local failure of dome

Figure 4 The impact experiment of reticulated dome by using a dropping machine(Source: Fan) 


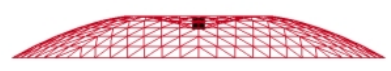

Local failure of dome

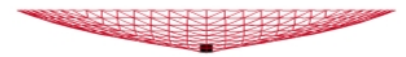

Global collapse of dome

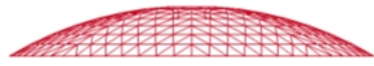

Shear failure of member

Figure 5 The failure modes of reticulated domes under impact load

The research on cable structures has so far been little. Huang Yan accurately developed a completely general analytical method for the static analysis of cable structures ${ }^{[11]}$. M. Wolff ${ }^{[12]}$ modeled a cable-stayed bridge, examined the dynamic response of a cable-stayed bridge to the loss of a cable, and evaluated the effects of cable sag, transverse cable vibrations and structural damping in nonlinear dynamic analyses. Mozos ${ }^{[13,14]}$ systematically studied on the response of cable stayed bridges, the pylons and the stays to the sudden rupture of one of its stays. Li Tian ${ }^{[15]}$ used the nonlinear static and dynamic analysis methods and adopted 3D finite element model, to study the responses to sudden breakage of hangers of self-anchored suspension bridge, and gave the suggestions for the improvement of structure safety.

\section{CONCLUSIONS}

Above all, large-span cable structure is widely used in large-scale public building, and is of great political and economic importance. Yet it has lots of safety problems and easily impacted by accidental loading during the using. However, almost all of the existed achievements are for the prevention of progressive collapse in frame structures, and most of the research results in large-span space structure are for the reticulated domes. The research on the impact resistance of large-span cable structure has so far been little, and most of them are for the cable stayed bridge. More attention should be paid on the dynamic response and failure mechanism of large-span cable structures under impact by referencing the existed achievements that research on the impact resistance of reticulated domes.

\section{ACKNOWLEDGMENTS}

This work has been conducted with the financial support from the science and technology research projects of the Heilongjiang Province Natural Science Foundation of China (E201438); The Education Department of Heilongjiang province (12531135); The National Natural Science Foundation of China (project designation: 51378164 and 50978077).

\section{REFERENCES}

[1] Shen Shizhao, Xu Chongbao, Zhao Chen, et al. Design of Cable Structures(2nd Edition)[M]. Beijing:China Architecture \& Building Press,2006(in Chinese)

[2] K. Abedi, G.A.R. Parke. Progressive collapse of Single-layer Braced Domes[J]. International Journal of Space Structure, 1996, 11(3): 291-306.

[3] K. A. Steffen. Progressive collapse of the World Trade Center: Simple Analysis[J]. Journal of Engineering Mechanics, 2008, 2: 125-132.

[4] Liang Yi, Lu Xinzheng, Li Yi, et al. Design method to resist progressive collapse for a three story RC frame[J]. Journal of PLA University of Science of Technology, 2007, 8(6): 659-664 
[5] Du Hao, Li Zhongxian, Hao hong. Numerical simulation on blast overpressure loading outside buildings[J]. Journal of PLA University of Science of Technology, 2007, 8(5): 413-418

[6] Guo Ke. Dynamic analysis of single-layer reticulated shells under impact[D]. Taiyuan: Taiyuan University of Technology, 2004 (in Chinese)

[7] Wang Duozhi, Fan Feng, Zhi Xudong, et al. Experimental study on single-layer reticulated dome under impact[J]. Journal of Building Structures, 2011, 32(8): 34-41(in Chinese))

[8] Lin Li, Fan Feng, Zhi XuDong, Yin HongFeng. Size effect and material property effect of the impactor on the damage modes of the single-layer Kiewitt-8 reticulated dome[J]. Scientific World Journal, 2013, 1: 1-7.

[9] Ma Jialu, Fan Feng, Wu Chengqing, Zhi Xudong. Counter-Intuitive Collapse of Single-Layer Reticulated Domes Subject to Interior Blast Loading[J]. Thin-Walled Structures, 2015, 96:130-138. [10] Ma Jialu, Wu Chengqing, Zhi Xudong, Fan Feng. Prediction of Confined Blast Loading in Single-Layer Lattice Shells[J]. Advances in Structural Engineering, 2014, 17(7): 1029-1043.

[11]Huang Yan, Lan Weiren. Static analysis of cable structure[J]. Applied Mathematics and Mechanics, 2006, 27(10): 1425-1430.

[12]Wolff M, Starossek U. Cable loss and progressive collapse in cable-stayed bridges[J]. Bridge Structures, 2009, 5(1): 17-28.

[13]Mozos C.M, Aparicio A.C. Parametric study on the dynamic response of cable stayed bridges to the sudden failure of a stay, Part I: Bending moment acting on the deck [J]. Engineering Structures, 2010,32: 3288-3300

[14]Mozos C.M, Aparicio A.C. Parametric study on the dynamic response of cable stayed bridges to the sudden failure of a stay, Part II: Bending moment acting on the pylons and stress on the stays[J]. Engineering Structures, 2010,32: 3301-3312

[15]Li Tian. Research of Self-anchored Suspension Bridge to Sudden Breakage of Hangers. Dalian University of Technology, 2015.) 